\title{
RESEARCH AND PRACTICE
}

\section{The role of perception in developing healthy lifestyles and community engagement}

\author{
Anne Marie Coleman PhD, MPH, ${ }^{1}$ Anne Hicks-Coolick, PhD, MSW, MEd, ${ }^{2}$ and Agnes F. Brown ${ }^{3}$ \\ ${ }^{1}$ Georgia Department of Public Health; ${ }^{2}$ Associate Professor Emeritus, Kennesaw State University; ${ }^{3}$ Cobb and Douglas Public Health \\ Department
}

\begin{abstract}
Background: The Cobb and Douglas Public Health Department and the Cobb2020 partnership, sponsored by the Mobilizing for Action through Planning and Partnering program, facilitated six focus groups in Cobb County to ascertain residents' perceptions of healthy behaviors. The purpose of the research was to assist in the development of programs to increase healthy behaviors.

Methods: Purposive sampling was used to choose fifty-eight participants, who were divided into six groups in different geographic locations. The focus group questions concerned healthy living, health communications, and community health. Qualitative data analysis techniques were used to generate themes and categories across and within groups.

Results: Six themes emerged: 1) need for education; 2) healthy food choices; 3) access to healthcare; 4) trust in health care providers; 5) affordable healthcare; and 6) need for local resources. The results show how community members' perceptions regarding: a) policies that affect health, b) environments that promote healthier choices, and c) systems that allow individuals to be health consumers influence healthy living and community engagement. Other findings note different perceptions between those with and without health insurance. In addition, socio-economic status and ethnicity were seen as factors related to the perceptions of participants.
\end{abstract}

Conclusions: The findings of this study informed a comprehensive, county-wide Community Health Improvement Plan. As a result of these studies, Cobb \& Douglas Public Health established, as two chronic disease prevention interventions, the Cobb2020 Farm Fresh Market and, in the City of Kennesaw, the 100\% Tobacco Free Parks and Cemeteries policy.

Keywords: focus group, healthy living, individual perceptions, health belief model

\section{INTRODUCTION}

For years, researchers have noted how individual perceptions affect healthy behavior. Yun and Silk (2011) showed how perceptions and social norms influence a person's ability to exercise regularly and maintain a healthy diet. Peterson, Schmer and Ward-Smith (2013) observed that attitudes and perceptions influence abilities of rural women to participate in regular physical activity. An individual's perception of worksite support may impact healthy behaviors (Lemon et al., 2009). In specific groups, perception influences tobacco dependence (Reitzel et al., 2012). Individual perception also affects preventive behavior in cardiovascular disease (Claassen et al., 2012). Furthermore, perception affects not only the health of patients but the health of their family members (Mazor, Goff \& Alper, 2009). This study reports the methodology used and the results and conclusions of focus groups in Cobb County, Georgia.

The current report presents findings on the perceptions of fifty-eight (58) participants in six focus groups in different geographic locations countywide and describes how the results were used to develop community interventions to reduce chronic diseases.

\section{Health Belief Model}

The theoretical framework for this study is embedded in the Health Belief Model (HBM). The HBM was developed on the basis of a person's readiness to change health-related behavior as a result of perceived susceptibility, perceived severity, perceived advantages, and perceived disadvantages. In addition, this model explains how perceptions and attitudes can be used in adopting healthy behaviors. The basic theory undergirding the HBM is that an individual will take a health-related action (e.g., going to the doctor, screening, or exercise) if that individual feels that a harmful health condition (in this case, obesity and other chronic diseases) can be prevented. In addition, the HBM is rooted in the individual's belief that the recommended intervention can be achieved successfully (Boskey, 2008). Finally, the HBM concludes that if a person believes a) there are benefits associated with a recommended behavior; b) those benefits outweigh the cost, time, and any other related factors of inconvenience; and c) that it is possible to gain control of the disease at hand, then it is possible to stimulate a positive health-related behavior. Boskey (2008) noted how health is multi-dimensional, and, to reach optimal health, certain factors, including biological makeup, psychological processes, and the social environment, should work together. The HBM has been used to motivate the general public to engage in making 
healthier choices regarding health as a way to decrease health disparities (Glanz, Lewis \& Rimer, 2002). Boskey (2008) noted how researchers and scientists use the HBM to predict health behaviors. This is imperative because healthy behaviors (e.g., going to the doctor, screening, and exercise) are linked to prevention of chronic diseases. In the present study, qualitative research methods were used to collect data about perceptions of local community members from Cobb County, the third largest county in Georgia.

\section{METHODS}

During the summer of 2012, Cobb \& Douglas Public Health in Cobb County, Georgia, facilitated a series of six (6) focus groups consisting of a total of fifty-eight (58) participants. These focus groups were part of the Community Health Improvement Plan of the Cobb2020 Partnership. Funding for the focus groups was provided through a Community Transformation Grant (CTG). Various professionals were involved in the planning and implementation of the groups. The group meetings were for two hours, including one hour for a meal and the second hour for the focus group.

\section{Sites and Participants}

The focus group meetings were held in Cobb County, Georgia, at various locations, including a) two community recreation centers $(\mathrm{n}=9$ and $\mathrm{n}=18)$; b) two apartment complexes ( $n=9$ and $n=7) ; c)$ an apartment clubhouse $(n=8)$; and d) a church $(n=7)$. Purposive sampling techniques (Patton, 2002) were used to choose the participants for each of the six groups. The groups had from seven to eighteen participants for a total of fifty-eight (58). They included three neighborhood civic groups, one group of volunteer health care workers for the Hispanic population, and a group of Hispanic parents. Participants were adults who largely represented minority populations in Cobb County and varied by gender, age, race, and socioeconomic levels (See Tables 1-4).

\begin{tabular}{|l|l|l|l|l|l|}
\hline \multicolumn{7}{|l|}{ Table 1. Percentage and Numbers for Races in Each of the Six Focus Groups } \\
\hline & $\mathrm{N}$ & Black & Hispanic & White & Other \\
\hline Group 1 & 18 & $87 \%(\mathrm{n}=15)$ & 0 & $13 \%(\mathrm{n}=2)$ & 0 \\
\hline Group 2 & 9 & $100 \%(\mathrm{n}=9)$ & 0 & 0 & 0 \\
\hline Group 3 & 8 & $75 \%(\mathrm{n}=6)$ & 0 & $12.5 \%(\mathrm{n}=1)$ & $12.5 \%(\mathrm{n}=1)$ \\
\hline Group 4 & 7 & $71 \%(\mathrm{n}=5)$ & 0 & $29 \%(\mathrm{n}=2)$ & 0 \\
\hline Group 5 & 7 & 0 & $100 \%(\mathrm{n}=7)$ & 0 & 0 \\
\hline Group 6 & 9 & 0 & $100 \%(\mathrm{n}=6)$ & 0 & 0 \\
\hline TOTAL & 58 & $60 \%(\mathrm{n}=35)$ & $22 \%(\mathrm{n}=13)$ & $10 \%(\mathrm{n}=5)$ & $2 \%(\mathrm{n}=1)$ \\
\hline
\end{tabular}

\begin{tabular}{|l|l|l|l|l|}
\hline \multicolumn{5}{|c|}{ Table 2. Percentages and Numbers for Genders in Each of the Six Focus Groups } \\
\hline & $\mathrm{N}$ & Male & Female & Missing Data \\
\hline Group 1 & 18 & $17 \%(\mathrm{n}=3)$ & $78 \%(\mathrm{n}=14)$ & $3 \%(\mathrm{n}=1)$ \\
\hline Group 2 & 9 & $33 \%(\mathrm{n}=3)$ & $67 \%(\mathrm{n}=5)$ & $11 \%(\mathrm{n}=1)$ \\
\hline Group 3 & 8 & 0 & $100 \%(\mathrm{n}=8)$ & 0 \\
\hline Group 4 & 7 & $29 \%(\mathrm{n}=2)$ & $57 \%(\mathrm{n}=4)$ & $14 \%(\mathrm{n}-=1)$ \\
\hline Group 5 & 7 & $29 \%(\mathrm{n}=2)$ & $71 \%(\mathrm{n}=5)$ & 0 \\
\hline Group 6 & 9 & $11 \%(\mathrm{n}=1)$ & $89 \%(\mathrm{n}=8)$ & 0 \\
\hline TOTAL & 58 & $19 \%(\mathrm{n}=11)$ & $76 \%(\mathrm{n}=44)$ & $5 \%(\mathrm{n}=3)$ \\
\hline
\end{tabular}

\begin{tabular}{|l|l|l|l|l|l|}
\hline \multicolumn{6}{|c|}{ Table 3. Percentages and Numbers for Ages in Each of the Six Focus Groups } \\
\hline & $\mathrm{N}$ & \multicolumn{1}{|c|}{$18-19$} & \multicolumn{1}{c|}{$20-34$} & $35-54$ & Over 55 \\
\hline Group 1 & 18 & 0 & $11 \%(\mathrm{n}=2)$ & $50 \%(\mathrm{n}=9)$ & $39 \%(\mathrm{n}=7)$ \\
\hline Group 2 & 9 & 0 & $11 \%(\mathrm{n}=1)$ & $55 \%(\mathrm{n}=5)$ & $34 \%(\mathrm{n}=3)$ \\
\hline Group 3 & 8 & 0 & $25 \%(\mathrm{n}=2)$ & $75 \%(\mathrm{n}=6)$ & 0 \\
\hline Group 4 & 7 & $14 \%(\mathrm{n}=1)$ & $14 \%(\mathrm{n}=1)$ & $72 \%(\mathrm{n}=5)$ & 0 \\
\hline Group 5 & 7 & 0 & 0 & $100 \%(\mathrm{n}=7)$ & 0 \\
\hline Group 6 & 9 & 0 & $67 \%(\mathrm{n}=6)$ & $33 \%(\mathrm{n}=3)$ & 0 \\
\hline TOTAL & 58 & $1 \%(\mathrm{n}=1)$ & $19 \%(\mathrm{n}=11)$ & $60 \%(\mathrm{n}=35)$ & $17 \%(\mathrm{n}=10)$ \\
\hline
\end{tabular}




\begin{tabular}{|l|l|c|c|c|c|c|c|}
\hline \multicolumn{7}{|c|}{ Table 4. Percentages and Numbers for Incomes in Each of the Six Focus Groups } \\
\hline & $\mathrm{N}$ & $>\$ 14999$ & $\begin{array}{c}\$ 15000- \\
\$ 24,999\end{array}$ & $\begin{array}{c}\$ 25000- \\
\$ 49,999\end{array}$ & $\begin{array}{c}\$ 50,000- \\
\$ 74,999\end{array}$ & $\$ 75,000+$ & Missing \\
\hline Group 1 & 18 & $17 \%(\mathrm{n}=3)$ & 0 & $33 \%(\mathrm{n}=6)$ & $17 \%(\mathrm{n}=3)$ & $28 \%(\mathrm{n}=5)$ & $\begin{array}{c}3 \% \\
(\mathrm{n}=1)\end{array}$ \\
\hline Group 2 & 9 & $11 \%(\mathrm{n}=1)$ & $22 \%(\mathrm{n}=2)$ & $22 \%(\mathrm{n}=2)$ & $44 \%(\mathrm{n}=4)$ & 0 & 0 \\
\hline Group 3 & 8 & $25 \%(\mathrm{n}=2)$ & $12.5 \%(\mathrm{n}=1)$ & $25 \%(\mathrm{n}=2)$ & $25 \%(\mathrm{n}=2)$ & 0 & $\begin{array}{c}12.5 \% \\
(\mathrm{n}=1)\end{array}$ \\
\hline Group 4 & 7 & $14 \%(\mathrm{n}=1)$ & $28 \%(\mathrm{n}=2)$ & $14 \%(\mathrm{n}=1)$ & $28 \%(\mathrm{n}=2)$ & $14 \%(\mathrm{n}=1)$ & 0 \\
\hline Group 5 & 7 & $14 \%(\mathrm{n}=1)$ & $71 \%(\mathrm{n}=5)$ & $14 \%(\mathrm{n}=1)$ & 0 & 0 & 0 \\
\hline Group 6 & 9 & $66 \%(\mathrm{n}=6)$ & $\begin{array}{c}1 \% \\
(\mathrm{n}=1)\end{array}$ & 0 & 0 & 0 & $\begin{array}{c}33 \% \\
(\mathrm{n}=2)\end{array}$ \\
\hline TOTAL & 58 & $24 \%(\mathrm{n}=14)$ & $19 \%(\mathrm{n}=11)$ & $21 \%(\mathrm{n}=12)$ & $19 \%(\mathrm{n}=11)$ & $10 \%(\mathrm{n}=6)$ & $\begin{array}{c}6 \% \\
(\mathrm{n}=4)\end{array}$ \\
\hline
\end{tabular}

\section{Data Collection}

Four of the focus groups were held in English; two were held in Spanish and translated into English. During each meeting, the leader asked seventeen (17) questions and audiotaped the entire group interaction (see Appendix 1). The researchers used two digital tape recorders to guarantee that all responses were captured. One researcher asked the questions, and the other took notes.

\section{Data Analysis}

The researchers used a general inductive approach to data analysis as described by Thomas (2005). The audiotape of each group was transcribed verbatim, and each transcription was checked against the original tape to verify accuracy. Recordings from the two focus groups conducted in Spanish were translated into English for analysis. The two researchers individually read and analyzed the content of the six transcripts using coding for themes and categories within groups. As a second step in the analysis, they negotiated and identified themes, including similarities and differences across groups. Ethnic and socioeconomic differences were also analyzed. The findings were supported by quotes of the participants.

\section{Trustworthiness}

Trustworthiness in qualitative data analysis includes techniques to ensure that an account is rich, robust, comprehensive, and well-developed (Cohen \& Crabtree, 2006). A report from the Robert Wood Johnson Foundation says that use of multiple analysts provides a check on selective perceptions of the researchers and indicates blind spots in interpretive analysis (Cohen \& Crabtree, 2006). In addition to researcher triangulation, the researchers used stakeholder checks that allowed personnel from the health department and other interested parties to comment on the findings and, thus, to increase credibility (Thomas, 2004). The focus group participants were invited to participate in group discussions on the implications of the results. The
CTG Program Manager and Policy Analyst coordinated the workshops in which findings were presented. The results of the focus groups were made public on the Cobb2020 webpage (www.cobb2020.com).

\section{RESULTS}

Although the themes that emerged were similar across sites, there were differences in perceptions depending upon socioeconomic and ethnic characteristics in each group. Participants from lower socio-economic neighborhoods perceived more problems than those from other areas. Those who had health insurance had fewer issues than those who did not have insurance. The Hispanic groups had more problems relative to their ethnicity than did other groups. However, the differences notwithstanding, consistent themes across groups were as follows: 1) health education, 2 ) healthy food choices, 3) access to healthcare, 4) trust in health care providers, 5) affordable healthcare, and 6) need for local resources.

\section{Health Education}

Many participants felt they were uninformed about health issues in the community. Comments describing a lack of communication to residents were seen in several responses such as, "there are [health] events we don't know about..." and "... some people can't go out; they can't travel to those places, or they can't get there or ... they may not have internet service." "If we just concentrate on educating the community and having a marketing campaign [concerning healthy living]..., I think it would work just as good as a policy." Another suggestion for educating the public was for the community to develop and print a "... a manual [of health related services]...to be provided so people would be educated." Another member of that group said, "However you have to get it out... send it through the mail, drop it by the doors." Another suggestion was to use "billboards like those for cigarettes but that speak of food; something like: if 
you eat this type of food, you will have cholesterol problems... something that alarms us."

\section{Healthy Food Choices}

Living alone, having a fast-paced lifestyle, not being able to pay the high cost for healthy food, and lacking space to grow fresh vegetables emerged as factors contributing to less healthy food choices. “... I'm single. If I go buy ... fruit and all this food, it will just go to waste. So then I find myself going ... [out to eat]." Another participant reported the fast food restaurants with high fat menus were cheaper and easily available in the community. Many mentioned that eating healthy food is more expensive than eating unhealthy food. One suggestion for saving money was [to buy] in bulk when products were on sale. Several participants reported the lack of space to garden as a limitation to healthy eating. "There are no places for us to grow our vegetables, the apartments are small, and there is no room for plant pots either."

Participants discussed the need for better food choices and consistency in providing healthy food options in the public school systems. One person described her concern about the school's food options conflicting with what she is teaching her children at home, "I worry about the schools because I have some control over what happens in my house, I can hide soda and give water to my family, take away chocolate and feed them carrots, but at school children get ice cream as a treat, this way whatever I do at home is worthless." Concern about vending machines and the products available to students was discussed, "... a bottle of water costs more than the soda," and the food options include "a lot of bread."

\section{Access to Healthcare}

Access to healthcare was a theme in all groups. Participants described a need for services for the disparate population. Some clinics that were available in the past are closed, "They've closed health departments in certain areas. We got a problem." "The services that are available currently ... are not adequate to meet the needs of the many people in the community." One participant spoke of a dilemma regarding a clinic that provides "healthcare for low income people." She explained the clinic is open two days a week and is free with a local doctor seeing patients, but by two o'clock, the line is so long many cannot get in. Another issue is related to the length of time to get an appointment, "When you call to make appointments at the health center, dates are very far." Furthermore, many agreed "the amount of time it takes to get results back on labs or on procedures can be extensive." One participant described the reason he did not like to seek care was the health system is too fragmented "... you go to one doctor and then you go to a specialist here and to another person. It just seems like it all don't gel together and it's just a little cumbersome to me. I'm just afraid of it."

\section{Trust in Healthcare Providers}

Many participants perceived a lack of trust in their healthcare providers. They did not know if tests ordered were always necessary, "Some of the recommendations ... (are not) necessarily best for us." Some participants had family members who could advise them or who could listen to what the doctor said and either confirm or negate it. Some believed there was a lack of confidence in the doctor's knowledge of medications and treatment because, "...you have to trust ...your doctor knows the side effects of the medicine and that he thinks ... these effects are less important than the illness." The perception of mistrust was also related to thinking that what the doctor charges and prescriptions may not be necessary. For instance, one said and others agreed, "The biggest problem is not having confidence in the doctor."

Some participants perceived they could not tell their doctor everything “....because of your fear of what they're going to think about you or say or that they may say something to someone else...." They discussed the limited amount of time providers spend with patients and their worry that doctors do not listen. One stated, "The doctor's time with you is getting shorter and shorter and shorter to a point where I don't even know if you get five minutes with the doctor." Others went on to say "...you don't have time to ask your questions or process what they're saying to you." "....Healthcare provider-patient relationship is so strained and so difficult that if you don't take an advocate with you, the chances are that the experience won't be positive...."

\section{Affordable Healthcare}

While many participants reported that they had health insurance coverage, each group had participants who did not. All individuals acknowledged the importance of having insurance coverage. "We cannot afford a doctor that will charge us $\$ 400$ just to see us, plus the medicines."

Participants spoke of the dilemma they face when their children are sick, "The free clinics take about 6 people in the time. And if you are only taking 6 people and 150 need health care... When I look at my baby's face and I see my baby sick and crying, you know what, I may take this twenty dollars and put some joy in his life, 'cause I gotta wait seven months to get to that doctor... So you don't know what it's like when you all always have healthcare and when you don't have healthcare."

\section{Need For Local Resources}

The final theme identified in all groups was the need for community resources to promote physical and emotional health and wellness. Participants believed that local gyms and church facilities would be helpful venues to promote physical activity by giving access to community members through joint-use agreements for their facilities. "We need a gym around this area. Some churches have gyms and exercise equipment ..." "I'd like to have an exercise room in my church parish." "I believe the gyms should be open to the community to go in and use that equipment. It's sitting there all weekend and all evening for free." "Yeah, I think it would be nice if schools opened up their outdoor facilities like their tracks during the mornings and the evenings for public use." "There are no big parks around here. There are some small green areas but no parks." Participants also noted having parks where smoking is prohibited as a need in their local community. People smoking in the parks was identified as a public health issue. Grocery stores with fresh produce or farmers markets were noted as needs by community members. "...There's not a grocery store in the community where I could shop." "All you've got is 
convenience stores around here. You don't buy healthy foods there."

\section{DISCUSSION}

For this exploratory study, there are several limitations, most of which are inherent in focus group research (Curtis $\&$ Redmond, 2007). For instance, the convenience sampling and small numbers of each group limit generalization to larger populations. Participants consisted of those who were active in the community and may not hold the same views as people who are less community-oriented. Many of the focus group participants were purposely chosen from disparate communities, such as lower economic or Hispanic areas. The views of these participants may differ substantially from upper-middle-class and upper-class individuals.

These results provide an opportunity to learn how local community members perceive variables directly related to making healthier choices and to being engaged in their community. The focus group participants shared information and how they perceived health, food choices, healthcare providers, tobacco prevention, and education. Public health professionals could apply the findings in making decisions on how to target policy, systems, and environmental changes towards chronic disease prevention at the local level. The perceptions of people should not be ignored in planning and developing interventions for prevention of chronic diseases. Throughout this research, participants explained how perceptions guided their decision-making, leading to their lifestyle choices. The information shared by the focus group participants reflected their individual realities and may not represent the final truth. What they perceived, however, was the driving force in how they made choices regarding their health.

Thus, health education for community members is not always clear; the message can be lost due to how it is perceived. To implement policy and environmental changes that lead to healthier lifestyle(s), health professionals need to communicate in a language that local community members can trust. Otherwise, barriers will prevent individuals from accepting and implementing healthy behaviors. Mass media campaigns should reach large numbers of people and be culturally sensitive, keeping in mind the diversity in the community. Since the roadmap to healthcare looks different to each community member, creating interventions where the access point is not generalized could help build trust and open doors for people to use the resources available to them.

\section{Current Health Related Interventions}

The Cobb2020 Partnership used the information from the focus groups to design and implement the Farm Fresh Market and worked to establish the $100 \%$ Tobacco Free Parks policy for a city in Cobb County. Both interventions are supported by evidence-based practices and, for community members, present policy and environmental change leading to sustainability. The goal of the Farm Fresh Market is to provide access to fresh produce to local community members of an identified food desert.
Evaluation results show that the market, implemented during the summer of 2014, provided access to fresh produce and increased the consumption of fruits and vegetables. The goal of the $100 \%$ Tobacco Free Parks Policy was to reduce exposure to second-hand smoke in a local park system. As a result of collaborations with community partners and local council members, the policy was adopted during the summer of 2014 .

Thus, community members should be included during the planning stages of program and policy development. Their contributions will ensure that public health practice(s) are not only implemented but that sustainable lifestyle changes are adopted. Community members should be partners, for their contributions, unlike others, can help translate the desired health outcomes, leading to decreases in morbidity and mortality associated with chronic disease. As described here, use of the Health Belief Model and learning from community members allowed for successful implementation of the two projects and, by engaging the community, ensured sustainability.

\section{References}

Boskey, E. (2008). Health Belief Model. Retrieved June 1, 2013, from http://std.about.com/od/education/a/healthbelief.htm.

Claassen, L., Henneman, L., van der Weijden, T., Marteau, T., \& Timmermans, D. (2012). Being at risk for cardiovascular disease: Perceptions and preventive behavior in people with and without a known genetic predisposition. Psychology, Health \& Medicine, 17, 511-521. doi:10.1080/13548506.2011.644246

Cobb2020 Partnership. Cobb2020 A Partnership for a Healthier Cobb County. Retrieved on

October 10, 2014, from http://cobb2020.com/en.html

Cohen, D. \& Crabtree, B. (July 2006). Qualitative Research Guidelines Project. Retrieved October 25, 2014 from http://www.qualres.org/

Curtis, E. \& Redmond, R. (2007). Focus groups in nursing research. Nurse Researcher. 14, 25-37.

Glanz, K., Lewis, F. M., \& Rimer, B. K. (2002). Health Behavior and Health Education: Theory, Research, and Practice (2 Ed.) Published by Jossey-Bass. Need city

Green, L.W. (2009). Health belief model. Retrieved June 1, 2013 from

http://www.answers.com/topic/health-belief-model.

Harrison, J. A., Mullen, P. D., \& Green, L. W. (1992). A metaanalysis of studies of the health belief model. Health Education Research 7, 107-116.

Janz, N. K., \& Becker, M. H. (1984). The health belief model: A decade later. Health Education Quarterly, 11, 1-47.

Lemon, S., Zapka, J., Li, W., Estabrook, B., Magner, R., \& Rosal, M. (2009). Perceptions of worksite support and employee obesity, activity, and diet. American Journal of Health Behavior, 33, 299-308.

Mazor, K. M., Goff, S. L., Dodd, K., \& Alper, E. J. (2009). Understanding patients' perceptions of medical errors. Journal of Communication in Healthcare, 2, 34-46.

Patton, M. Q. (2002). Qualitative Research and Evaluation Methods. Thousand Oaks, CA: Sage

Publishing.

Peterson, J., Schmer, C., \& Ward-Smith, P. (2013). Perceptions of Midwest Rural Women

Related to Their Physical Activity and Eating Behaviors. Journal of Community Health Nursing, 30, 72-82. doi:10.1080/07370016.2013.778722

Reitzel, L. R., Vidrine, J. I., Businelle, M. S., Kendzor, D. E., Cao, Y., Mazas, C. A., \& Wetter, D. W. (2012). Neighborhood Perceptions Are Associated With Tobacco Dependence Among 
African American Smokers. Nicotine \& Tobacco Research, 14, 786-793

Thomas, D. R. (2006). A general inductive approach for analyzing qualitative evaluation data.

American Journal of Evaluation, 27, 237-246. doi: $10.1177 / 1098214005283748$.
Yun, D., \& Silk, K. J. (2011). Social Norms, Self-identity, and Attention to Social Comparison

Information in the Context of Exercise and Healthy Diet Behavior. Health Communication, 26, 275-285. doi:10.1080/10410236.2010.549814 


\section{Appendix I}

\section{Focus Group Questions}

1. What does being healthy or health mean to you?

2. Who is responsible for the health of a community?

3. What do you usually do when you get sick? Where do you go to get help? Who do you usually see? How do you pay for it?

4. What keeps you from seeking healthcare services when you need them? How could you prevent that from happening?

5. Tell me about your experience with getting an annual physical.

6. What kind of health services are still needed that we do not currently have in Cobb County?

7. How does weight affect a person's health?

8. When you hear the word "overweight", what does that mean to you? What about the word "obesity"?

9. How do you decide what to eat?

10. What helps you to "eat healthy"? What makes it difficult to do so?

11. What are some things that help you be active?

12. What keeps you from being active?

13. Tell me about how money influences what you choose to eat? How does it influence how active you are?

14. What do you think about insurance companies charging higher premiums to people who smoke or are overweight or obese?

15. What could we do in Cobb County to increase people's health and healthy behaviors, like eating healthy, not smoking and being more active?

16. What other health issues in your community are a concern to you?

17. What are some health related policies that if passed could make it easier for people to eat healthier and exercise more? 